\title{
On the genetics of mandibular prognathism: analysis of large European noble families
}

\author{
G Wolff, T F Wienker, H Sander
}

\begin{abstract}
Mandibular prognathism is assumed to be a polygenic trait in the vast majority of cases. In a few families, this phenotype and perhaps a syndrome with a broader spectrum of facial anomalies seems to be determined by a single dominant gene of very low frequency (McKusick No $\left.{ }^{*} 176700\right)$. The phenotype is known to have occurred independently in several European noble families. We constructed a pedigree comprising 13 of these families with 409 members in 23 generations in which mandibular prognathism has been segregating. Obviously, the presumed dominant gene is not fully penetrant in the heterozygous state. Pedigree analysis using the Elston-Stewart algorithm yields a maximum likelihood estimate (MLE) of $p=.0 .955$ (SE 0.038) of the penetrance parameter.
\end{abstract}

(f Med Genet 1993;30:112-16)

Mandibular prognathism (McKusick No *176700) is one of the best known examples of a facial genetic trait in humans. According to the classification of Angle, ${ }^{1}$ this phenotype corresponds to class III skeletal malocclusion, the frequency of which in children was found to be in the range of $0.5 \%{ }^{2}$ to $2.7 \%,{ }^{3}$ and in mixed and permanent dentition in the range of 2 to $4 \%$ with a slight preponderance of affected males. ${ }^{45} \mathrm{~A}$ wide range of environmental factors has been suggested as contributing to the development of mandibular prognathism, ${ }^{6}$ but the observation of familial aggregation lends support to the hypothesis that heredity plays a substantial role in the aetiology. Numerous studies have shown a significantly higher incidence of this phenotype in the relatives of affected probands. ${ }^{6-10}$ In the offspring of affected parents, extensive studies of Japanese families showed a frequency of $18 \%$ if the mother was affected, $31 \%$ if the father was affected, and $40 \%$ if both parents were affected. ${ }^{711}$ In sibs of affected probands, Litton $e t$ $a l^{6}$ found a frequency of $13 \%$ irrespective of sex. The genetic mechanisms which have been suggested as being responsible for the phenomenon of familial aggregation of mandibular prognathism include 'irregular' inheritance with a penetrance of $70 \%$ and variable expressivity, ${ }^{9}$ autosomal recessive inheritance, ${ }^{712}$ autosomal dominant inheritance, ${ }^{813}$ dominant inheritance as a rule with some exceptions, ${ }^{14}$ dominant inheritance with incomplete penetrance, ${ }^{10}$ and a polygenic threshold model ${ }^{6}$ Concordance for prognathism among twin pairs collected from published reports was 17/
$21(81 \%)$ for monozygotic and $2 / 15(13 \%)$ for dizygotic twin pairs, ${ }^{15}$ a result which, according to Penrose, ${ }^{16}$ strongly argues against a monogenic aetiology in most of the affected. Taken together, these findings show that in the vast majority of families mandibular prognathism seems to have a polygenic or multifactorial cause.

Nevertheless there are reports of striking examples of apparently autosomal dominant inheritance of mandibular prognathism, the best known of which is the Habsburg family together with other European royal families. ${ }^{1718}$ Consanguinity was common in these families and has previously been suggested as accounting for the dominant 'Habsburg jaw'19 or discussed as a contributing factor acting on a multifactorial background..$^{18}$ Although it may be true that consanguinity contributed to some of the other disorders which the Habsburg family suffered from, it seems unlikely to be responsible for a phenomenon like pseudodominance of prognathism. ${ }^{20}$

There are only a few other reports of familial mandibular prognathism inherited in a way that suggests the existence of an autosomal dominant gene responsible for this phenotype. Stiles and Luke ${ }^{10}$ reported involvement in four generations with apparent non-penetrance in an obligate gene carrier, and McKusick ${ }^{21}$ observed the trait in a black family. Thompson and Winter ${ }^{20}$ described a three generation family with mandibular prognathism and other facial characteristics similar to those observed in members of the Habsburg family, such as thickened lower lip, prominent nose, flat malar areas, and mildly everted lower eyelids. One child had an oxycephalic head shape owing to synostosis of all cranial sutures, a feature which the authors suspected also in Charles V, a severely affected member of the Habsburg family.

It can therefore be hypothesised that there might be an autosomal dominant gene of reduced penetrance possibly leading to a syndrome of variable clinical expressivity with mandibular prognathism as the main feature and a variable spectrum of other cranial and facial anomalies as optional symptoms.

To prove this hypothesis we analysed an extended pedigree of European noble families in which mandibular prognathism was segregating.

\section{Methods and results}

A pedigree was constructed comprising 13 European noble families with 409 members in 23 generations (fig 1). The physical status with regard to mandibular prognathism of each of 


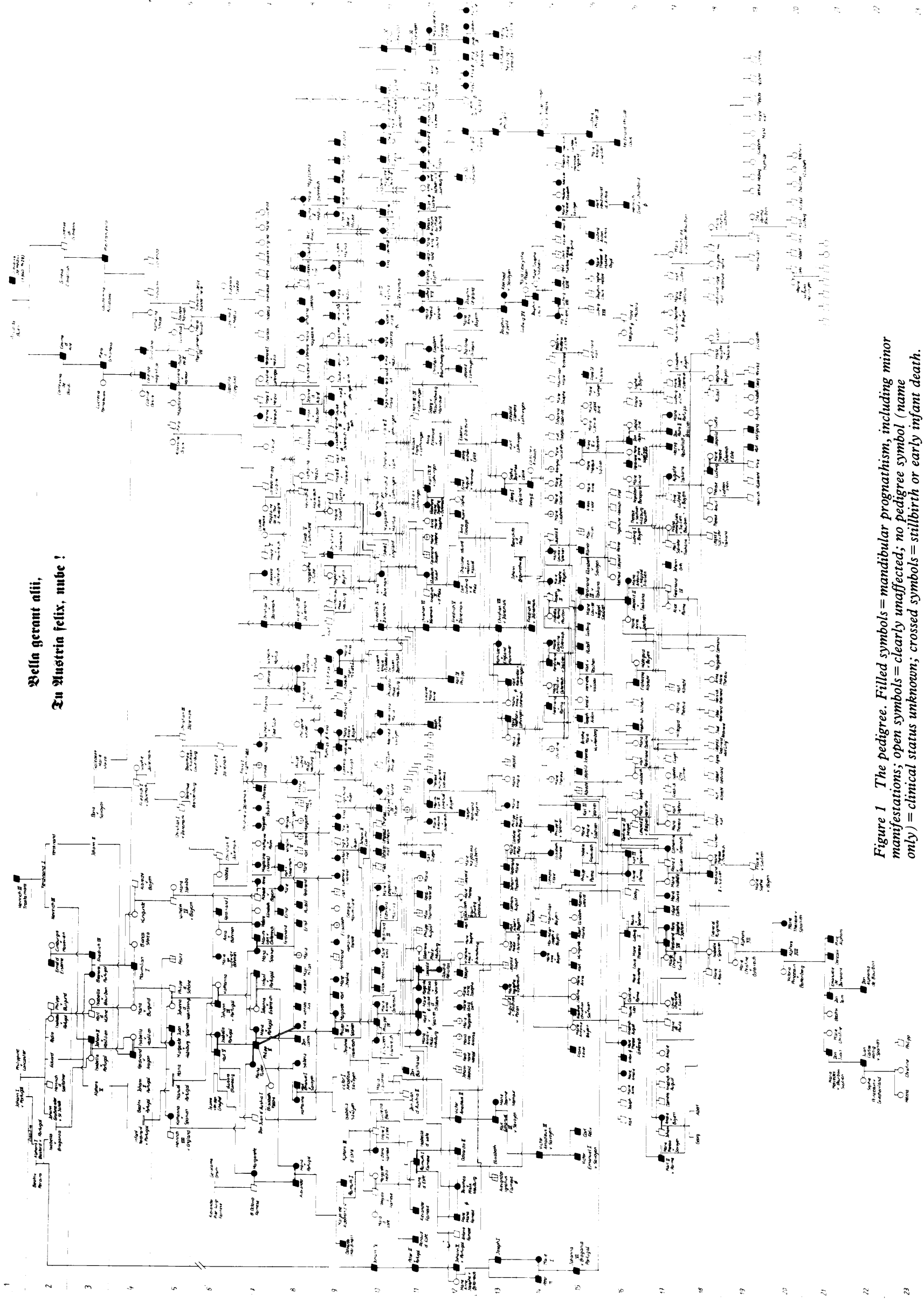


these family members was documented by means of pictures (fig 2) or authentic descriptions. ${ }^{22}$ Family members exhibiting only minor symptoms of the trait like everted lower lip were also regarded as affected. Segregation of the phenotype in the offspring of consanguin-

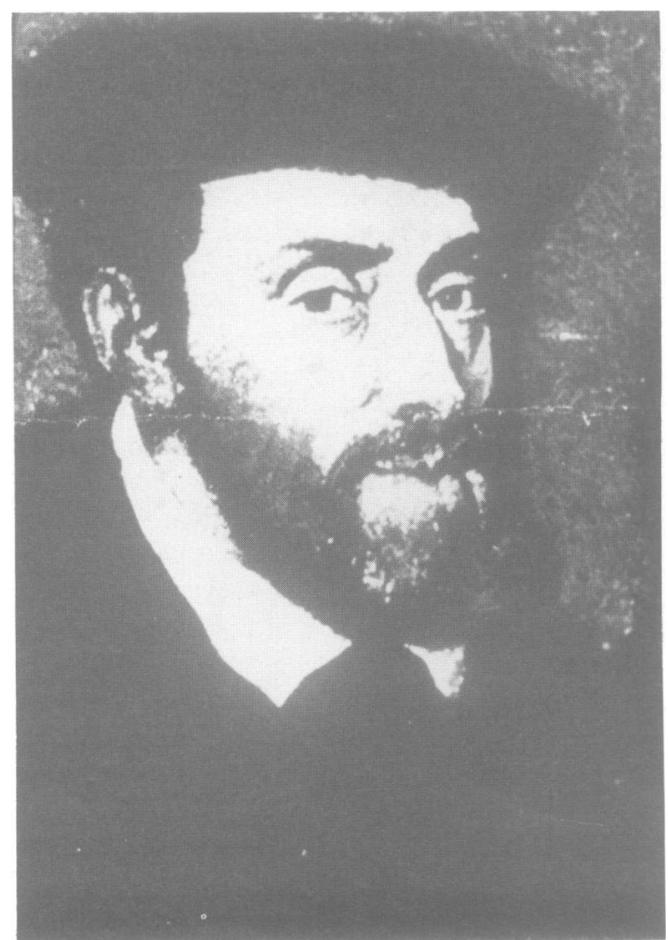

Figure $2 A \quad K a r l V$ (6th generation, fig 1). Painting of Tizian, reproduced from B Hamann, ed. Die

Habsburger. München: Piper Verlag, 1988: 201 (detail).

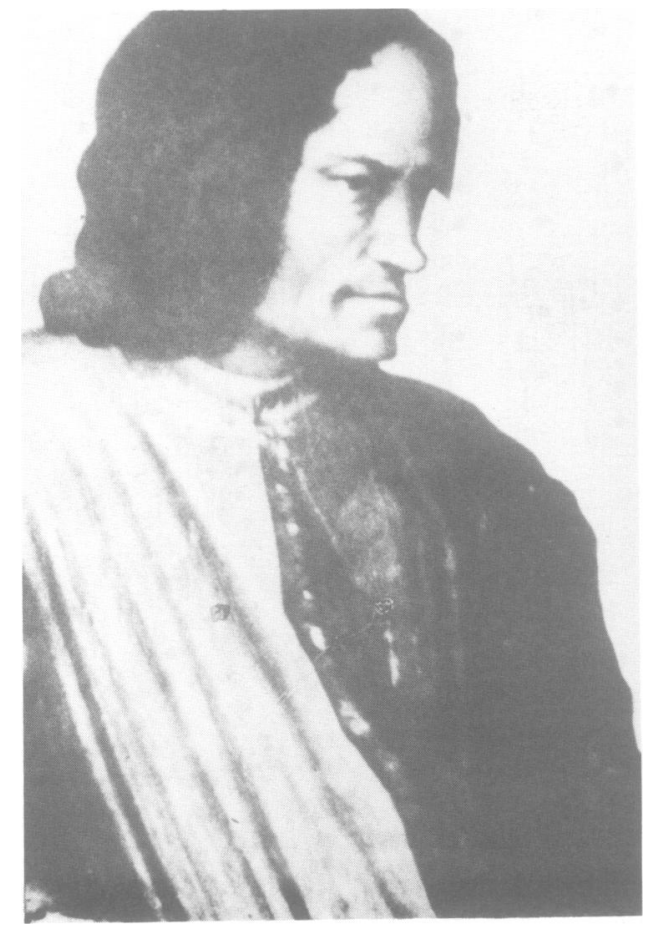

Figure 2B Lorenzo il Magnifico di Medici (4th generation, fig 1). Painting of Christofano dell'Altissimo, reproduced from Karla Langedijk. The portraits of the Medici, 15th-18th centuries. Firenze: Studio per Edizioni Scalte, 1983: 1138.

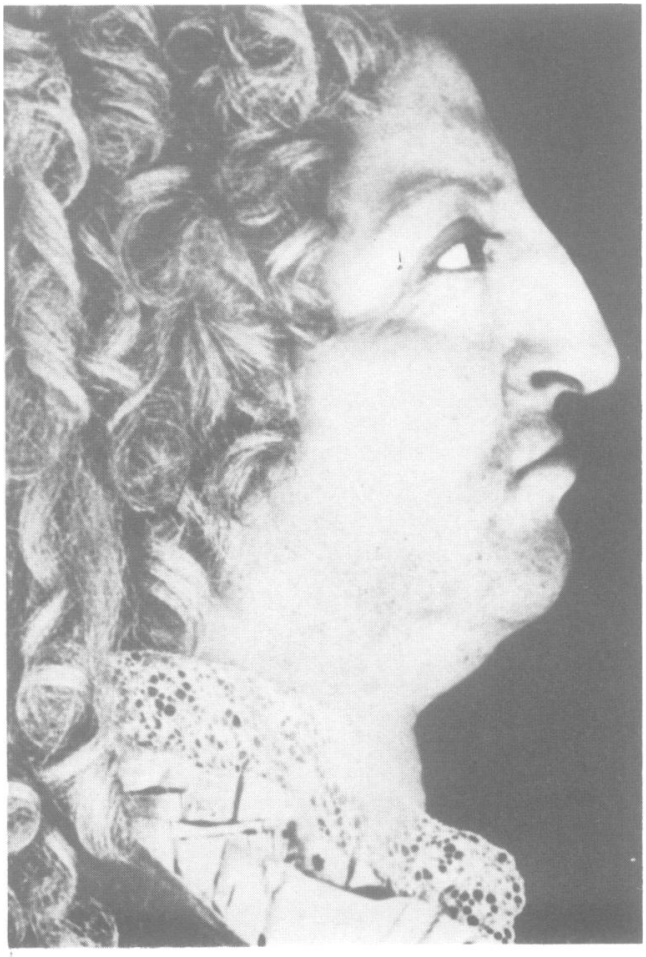

Figure $2 C$ Louis XIV (11th generation, fig 1). Wax impression, reproduced from René de la Croix Herzog von Castries: Die Bourbonen in Frankreich. In: Die großen Dynastien. München: Südwest Verlag, 1978: 170

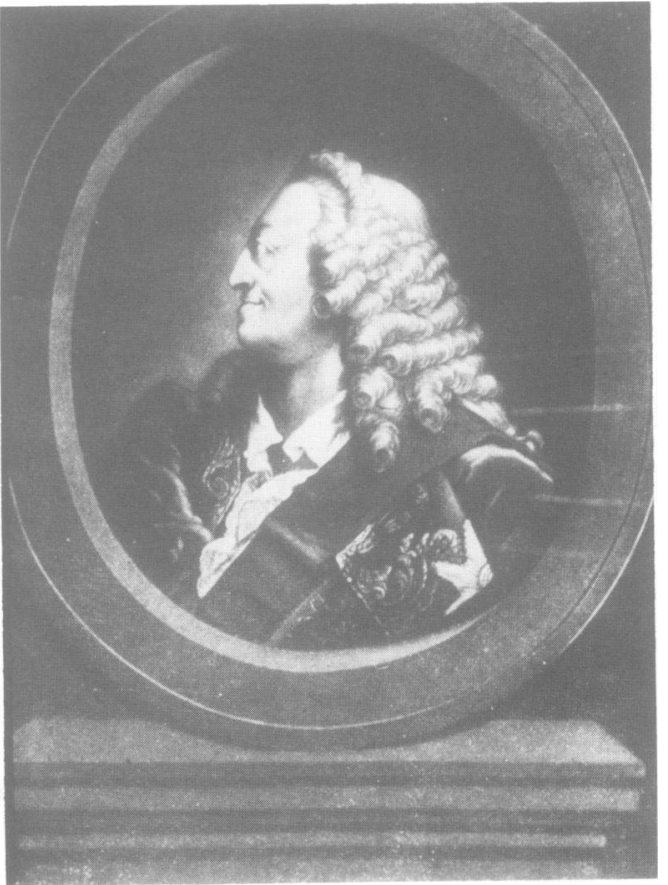

Figure 2D George II (14th generation, fig 1).

Mezzotint engraving of Richard Houston, reproduced from $M v$ Boehn. England im 18. Jahrhundert. Berlin: Askanischer Verlag, 1920:64. 


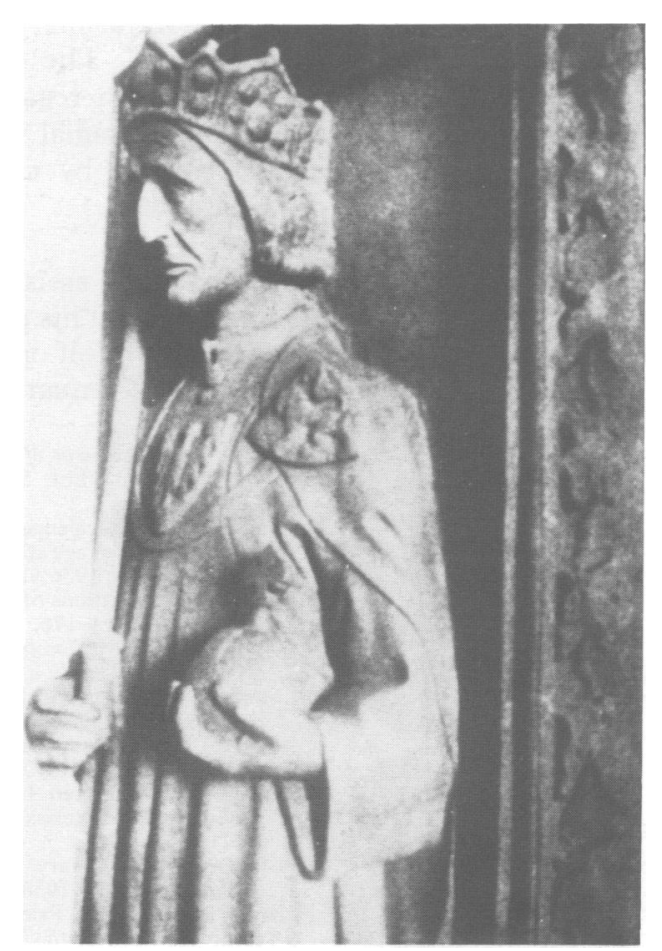

Figure $2 E$ Rudolph I von Habsburg (not included in the pedigree, the great great grandfather of Ernst der Eiserne (generation 1). Photograph taken from the gravestone in Speyer Cathedral, privately owned by one of the authors.

eous and non-consanguineous affected parents was analysed by separately estimating the segregation ratio of affected/unaffected children in families with one and both parents affected (figs $3 \mathrm{~A}-\mathrm{D})$. In all situations affected offspring were more frequent than unaffected,
A
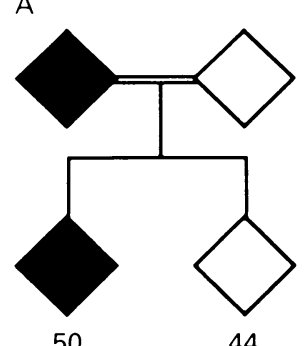

44

C
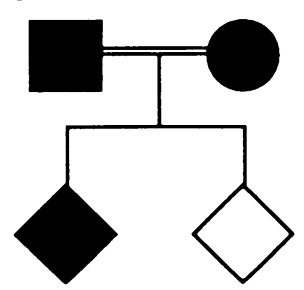

93
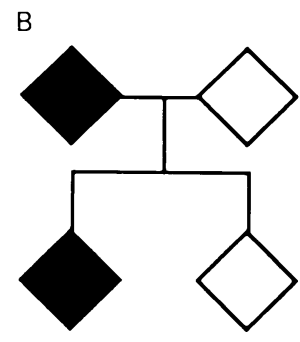

65

D

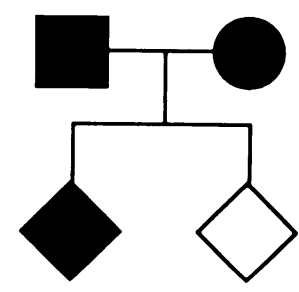

16

3
Figure 3 Segregation of the mandibular prognathism phenotype in the offspring of consanguineous and non-consanguineous affected parents. $(A$ ) one parent affected + consanguinity, $B$, one parent affected, no consanguinity, $(C)$ both parents affected + consanguinity, (C) both parents affected +
consanguinity, $(D$, both parents affected, no consanguinity. In all situations affected offspring are more frequent than unaffected, but only in $C$, does this observation differ significantly from the ratio expected under the assumption of autosomal dominant inheritance. but only in the offspring of consanguineous parents who were both affected did the ratio differ significantly from the $1: 1$ expected under the assumption of autosomal dominant inheritance.

Obviously, the gene is not fully penetrant in the heterozygous state. A direct estimate by counting the fraction of 'skipped generations' (fig 4) yielded a crude estimate of penetrance of 0.88 . In order to obtain an empirical estimate of the penetrance parameter $(\mathrm{p})$, the likelihood of the pedigree was repeatedly calculated using the Elston-Stewart algorith $\mathrm{m}^{23}$ and maximised over this parameter with all other parameters held constant (gene frequency 0.0001, complete penetrance in the homozygous state).

The LIPED computer program ${ }^{24}$ was chosen since it is a fairly fast and reliable way to handle large and complex pedigrees with multiple consanguinity loops. However, the large pedigree had to be broken down into four parts which did not overlap except for the key ancestors, otherwise computation times (mainframe IBM 3090 180E, VS-Fortran 2.4.0) exceed all bounds. Thus, we obtained a maximum likelihood estimate (MLE) of the penetrance parameter, $\mathrm{p}$ (fig 5).

According to standard likelihood theory, the variance of the MLE equals the negative inverse of the second derivative of the likelihood function at its maximum. A second order polynomial approximation around the maximum ${ }^{25}$ yields $\mathrm{p}=0.955$ (SE 0.038). Approximation by higher order polynomials $(3,4,5)$ did not substantially alter the MLE or its standard error. Changing the allele frequency up to 0.001 also did not lead to substantially altered results.

\section{Discussion}

Segregation of the mandibular prognathism phenotype in this large pedigree (fig 1) strongly argues in favour of a single dominant gene. The slight preponderance of affected children among the offspring of affected parents (fig 3) could be explained by some of the parents being homozygous for the presumed dominant gene. Looking for a possible effect of this suspected homozygous state, we found no hint of lethality or a more severe clinical expression of the phenotype among the offspring of two affected parents. In concordance with this finding is the observation that most of the very severely affected members, including Charles V, did not have parents who were both affected.

Generally, ascertainment is a major problem in estimating the penetrance parameter(s) by

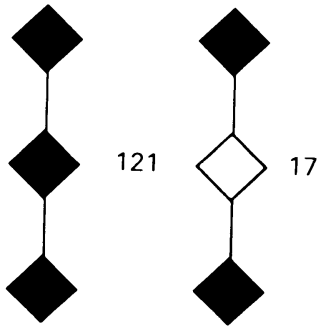

Figure 4 Estimation of the penetrance of the presumed autosomal presumed autosomal
dominant gene by the direct method $(87.7 \%$, 
Penetrance

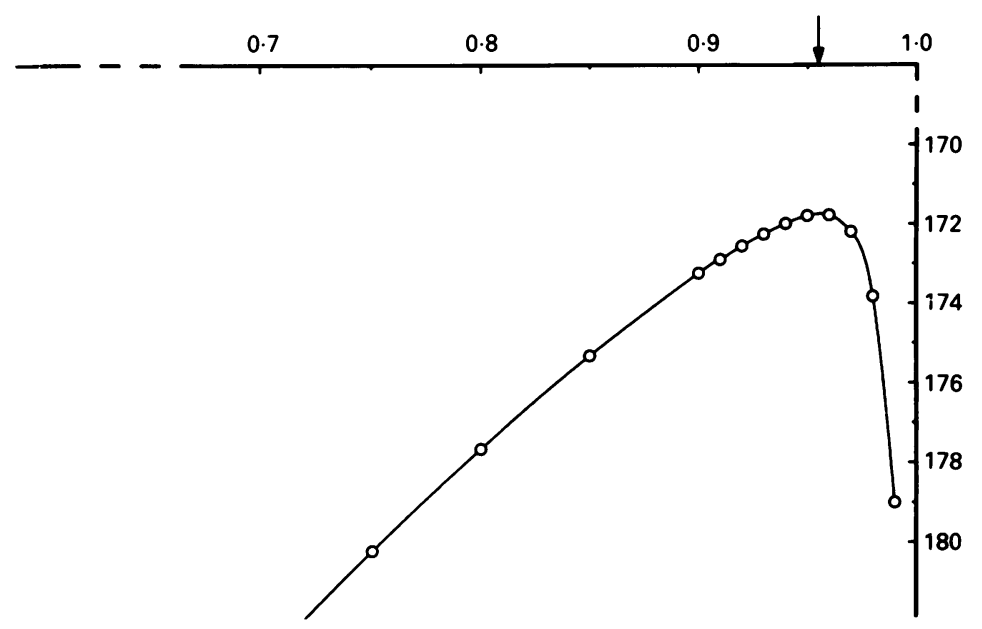

Figure 5 Likelihood of the pedigree versus penetrance (horizontal axis). Logarithmic scale of total likelihoods plotted on the vertical axis. Maximum estimate and its standard error by quadratic interpolation.

pedigree analysis. In the case of an autosomal dominant gene, there are several ways to counteract or correct for ascertainment bias. ${ }^{2627}$ However, if penetrance of a dominant gene can be estimated from a single large pedigree, ascertainment bias plays a lesser role if subsequent collection and documentation of pedigree members is independent of the phenotypic target condition. This can be safely assumed to be the case regarding mandibular prognathism in European noble lineages.

We paid particular attention to not introducing additional bias by cutting the pedigree into manageable parts. The advantages of a single large pedigree are clearly compromised by this procedure. Apart from the problem of bias there is a loss of power to be expected, that is, variance increase of the MLE. Some experimentation with different ways of dividing the pedigree did show, however, that both effects apparently are not substantial: the wealth of data provided by this pedigree overrides methodological shortcomings and compromise.

In summary, the mandibular prognathism phenotype segregating in related families of European high nobility is determined by a single autosomal dominant gene of high penetrance $(0 \cdot 95)$. Nevertheless, there is a considerable variation in expression ranging from protruding lower lip to orofacial malformation with malocclusion and functional impairment $^{22}$ (fig 2). The clinical spectrum of this phenotype with regard to more severe facial and perhaps cranial malformations has yet to be determined by careful documentation of other families.

The secretarial assistance of Mrs Wurich is acknowledged. This paper is dedicated to Professor Ulrich Wolf on the occasion of his 60th birthday on 2 January 1993.

1 Angle EH. Treatment of malocclusion of the teeth. 7th ed. Philadelphia: White SS Manufacturing Co, 1907:524,58,550-3.

2 Newman GB. Prevalence of malocclusion in children six to fourteen years of age and treatment in preventable cases. $\mathcal{F}$ Am Dent Assoc 1956;52:566.

3 Seipel CM. Variations of tooth position. Svensk Tandlak $T$ 1946;39(suppl):1-176.

4 Myllärniemi S. Malocclusion in Finnish rural children: an epidemiological study of different stages of dental development. Doctoral thesis, University of Helsinki, 1970.

5 Jorgenson RJ. Mandibular prognathism. In: Buyse ML, ed. Birth defects encyclopedia. Cambridge: Blackwell ScienBirth defects encyclopedia. Cam
tific Publications, 1990:1098.

6 Litton SF, Ackerman LN, Isaacson RJ, Shapiro BL. A genetic study of class III malocclusion. Am $\mathcal{f}$ Orthod 1970;58:565-77.

7 Iwagaki $\mathrm{H}$. Hereditary influence of malocclusion. $\mathrm{Am} \mathcal{f}$ Orthod Oral Surg 1938;24:328-36.

8 Kraus BS, Wise WJ, Frie RA. Heredity and the craniofacial complex. Am $\mathcal{F}$ Orthod 1959;45:172-217.

9 Schulze C, Wiese W. Zur Vererbung der Progenie. Fortschr Kieferorthop 1965;26:212-29.

10 Stiles KA, Luke JE. The inheritance of malocclusion due to mandibular prognathism. $f$ Hered 1953;44:241-5.

11 Suzuki S. Studies on the so-called reverse occlusion. $f$ Nihon Univ Sch Dent 1961;5:51-8.

12 Downs WG. Studies in the causes of dental anomalies. $f$ Dent Res 1928;8:367-79.

13 Keeler CE. Heredity in dentistry. Dent Cosmos 1935;77:1147.

14 Rubbrecht $O$. Study of the heredity of the anomalies of the jaws. Am Orthodont 1939;25:751-79.

15 Stewart RE, Prescott GH. Oral facial genetics. St Louis: CV Mosby, 1976:96.

16 Penrose LS. The genetical background of common diseases. Acta Genet 1953;4:257-65.

17 Rubbrecht O. L'origin du type familial de la maison de Habsburg. Bruxelles: van Oost et Cie, 1910.

18 Strohmayer W. Die Vererbung des Habsburger Familientypus. Nova Acta Leopoldina 1937;5:219-96.

19 Grabb WC, Hodge GB, Dingman RO, O'Neal RM. The Habsburg jaw. Plast Reconstr Surg 1968;42:442-5.

20 Thompson EM, Winter RM. Another family with the Habsburg jaw. I Med Genet 1988;25:838-42.

21 McKusick VA. Mendelian inheritance in man. 9th ed. Baltimore: Johns Hopkins University Press, 1990, No 176700.

22 Sander H. Die Vererbung der Progenie im Hochadel Europas. Inaugural Thesis, Faculty of Medicine, University of Inaugural Thesis,

23 Elston RC, Stewart J. A general model for the genetic analysis of pedigree data. Hum Hered 1971;21:523-42.

$24 \mathrm{Ott} \mathrm{J}$. A computer program for linkage analysis of general human pedigrees. Am $\mathcal{F}$ Hum Genet 1976;28:528-9.

25 Edwards AWF. Likelihood. London: Cambridge University Press, 1972. Reprint 1987.

26 Greenberg DA. Inferring mode of inheritance by comparison of lod scores. Am $\mathcal{\Im}$ Hum Genet 1989;34:480-6.

27 Ott J. Analysis of human genetic linkage. Revised edition. Baltimore: Johns Hopkins University Press, 1991. 